\title{
Sensitivity of aerosol radiative effects to different mixing assumptions in the AEROPT 1.0 submodel of the EMAC atmospheric-chemistry-climate model
}

\author{
K. Klingmüller ${ }^{1}$, B. Steil ${ }^{2}$, C. Brühl ${ }^{2}$, H. Tost ${ }^{3}$, and J. Lelieveld ${ }^{1,2}$ \\ ${ }^{1}$ The Cyprus Institute, P.O. Box 27456, 1645 Nicosia, Cyprus \\ ${ }^{2}$ Max Planck Institute for Chemistry, P.O. Box 3060, 55020 Mainz, Germany \\ ${ }^{3}$ Institut für Physik der Atmosphäre, Johannes Gutenberg-Universität Mainz, 55099 Mainz, Germany \\ Correspondence to: K. Klingmüller (klingmueller@cyi.ac.cy)
}

Received: 18 February 2014 - Published in Geosci. Model Dev. Discuss.: 16 May 2014

Revised: 29 August 2014 - Accepted: 15 September 2014 - Published: 28 October 2014

\begin{abstract}
The modelling of aerosol radiative forcing is a major cause of uncertainty in the assessment of global and regional atmospheric energy budgets and climate change. One reason is the strong dependence of the aerosol optical properties on the mixing state of aerosol components, such as absorbing black carbon and, predominantly scattering sulfates. Using a new column version of the aerosol optical properties and radiative-transfer code of the ECHAM/MESSy atmospheric-chemistry-climate model (EMAC), we study the radiative transfer applying various mixing states. The aerosol optics code builds on the AEROPT (AERosol OPTical properties) submodel, which assumes homogeneous internal mixing utilising the volume average refractive index mixing rule. We have extended the submodel to additionally account for external mixing, partial external mixing and multilayered particles. Furthermore, we have implemented the volume average dielectric constant and Maxwell Garnett mixing rule. We performed regional case studies considering columns over China, India and Africa, corroborating much stronger absorption by internal than external mixtures. Wellmixed aerosol is a good approximation for particles with a black-carbon core, whereas particles with black carbon at the surface absorb significantly less. Based on a model simulation for the year 2005, we calculate that the global aerosol direct radiative forcing for homogeneous internal mixing differs from that for external mixing by about $0.5 \mathrm{~W} \mathrm{~m}^{-2}$.
\end{abstract}

\section{Introduction}

The limited quantitative understanding of aerosols chiefly contributes to uncertainty in radiative forcing estimates and climate simulations. The industrial era forcing (relative to the year 1750) by the direct radiative effect is estimated at $-0.27 \mathrm{~W} \mathrm{~m}^{-2}$ with a $90 \%$ uncertainty interval of -0.77 to $0.23 \mathrm{~W} \mathrm{~m}^{-2}$ (IPCC, 2013). The direct forcing is complemented by the indirect effects via cloud adjustment through aerosol particles acting as cloud condensation nuclei; this forcing is estimated at $-0.55 \mathrm{~W} \mathrm{~m}^{-2}(-1.33$ to $-0.06 \mathrm{~W} \mathrm{~m}^{-2}$ ) (IPCC, 2013). Despite the large uncertainty, the increase in the cloud droplet number due to growing aerosol concentrations is generally recognised to exert a negative forcing and cooling effect by enhancing the reflection of solar radiation. While the indirect effects may have been large during the early period of industrialisation and pollution emissions, their significance has probably been smaller in recent decades and will be so in future (Carslaw et al., 2013).

On the other hand, predominantly scattering aerosol components are competing with absorbing carbonaceous components (black carbon) in the direct effect, and at present the uncertainty range does not rule out a net warming. Recently, the best estimate for the industrial era direct radiative forcing of atmospheric black carbon has been proposed to be as high as $0.71 \mathrm{~W} \mathrm{~m}^{-2}\left(0.08\right.$ to $1.27 \mathrm{~W} \mathrm{~m}^{-2}$ ) (Bond et al., 2013), which, to large extent, compensates for the negative radiative forcing contributions of mineral dust, sulfate, nitrate and organic carbon. Thus, even to capture the sign of 
the net direct effect, the uncertainties need to be drastically reduced in model simulations.

The large uncertainties have multiple origins, including insufficient knowledge of the emitted aerosol particles and their gaseous precursors, strong spatial and temporal variations of the aerosol concentrations, and complex chemical ageing and coagulation processes transforming the aerosol particles during their lifetime in the atmosphere. A major source of uncertainty is the strong dependence of the aerosol optical properties on the mixing state of the aerosol components. This demands a better understanding of the mixing state found in atmospheric aerosols on the one hand, and on the other hand the implementation of realistic mixing states in climate models, in particular in global chemistry-climate models, such as the ECHAM/MESSy (ECMWF model Hamburg version/Modular Earth Submodel System) atmosphericchemistry-climate model (EMAC) (Jöckel et al., 2005, 2006).

Most climate models assume the atmospheric-aerosol mixture of chemical constituents to be either internal, assuming homogeneous particles, or external (Fig. 1), possibly allowing a combination of both. Easter et al. (2004) list 16 models, five using external mixing, two internal mixing and the remaining models using a combination of both. EMAC also uses a combination by assuming internal mixing within externally mixed modes, similarly to, e.g., ECHAMHAM (Hamburg aerosol model) (Zhang et al., 2012) and MIRAGE (Model for Integrated Research on Atmospheric Global Exchanges) (Easter et al., 2004). Generally, external mixtures are less absorbing than internal mixtures, as the increased cross section affected by absorbing components in an internal mixture outweighs the decreased absorption per cross section. Therefore, external and internal mixtures typically under- and overestimate, respectively, absorption of solar radiation if not used appropriately. Only few global simulations consider core-shell particles, e.g. Jacobson (2000, 2001) and Kim et al. (2008).

Here, we use the EMAC model, which includes the aerosol optical properties submodel AEROPT (AERosol OPTical properties) (Lauer et al., 2007; Pozzer et al., 2012), which primarily mixes different aerosol components internally, assuming a homogeneous mixture. This rather idealised mixing state is probably representative of chemically aged particles and used for simplicity but, as mentioned above, can overestimate aerosol absorption. In reality, aerosol particles form coated spheres or are externally mixed, especially close to the emission sources. Ideally, the model provides all mixing states from external mixing through core-shell mixing to well-mixed internal mixtures and calculates the optimal configuration online, depending on chemical processing and coagulation during atmospheric transport. For this study, we have extended AEROPT by external mixing, partial external mixing, multilayered particles and two alternative mixing rules. At this stage, the mixing state within each mode is chosen offline ahead of each simulation, whereas interactive
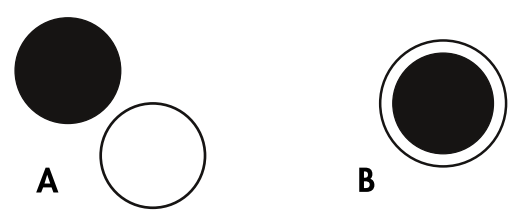

B

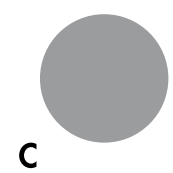

Figure 1. Schematic illustration of three mixing states. In externally mixed aerosols different types of particles coexist, each consisting of a single component (a), whereas in internally mixed aerosols the particles consist of a combination of components $(\mathbf{b}, \mathbf{c})$. An internal mixture can be either inhomogeneous, e.g. having a core-shell structure (b), or homogeneous (c). External mixtures (a) are least absorbing, as the increased cross section affected by absorbing components in an internal mixture $(\mathbf{b}, \mathbf{c})$ outweighs the decreased absorption efficiency.

computations are planned for future applications. However, as fresh black carbon is emitted into hydrophobic modes where it is separated from components in the hydrophilic modes to which it can subsequently be transferred, a transition from external to internal mixing is already accounted for, similar to Ghan et al. (2012).

A key aspect of this work is the comparison of internal and external mixing within the aerosol modes, which we study in regional case studies and a global simulation. It provides an envelope of optical properties and their impact on the associated climate forcing by anthropogenic aerosol constituents for several mixing states. In addition, we address alternative mixing rules and core-shell particles, for which we present regional results.

This article is structured as follows: we briefly review the relevant mixing states in Sect. 2, including the equations used in our aerosol optical property code AEROPT; Sect. 3 describes how the aerosol optical properties are processed in EMAC and introduces a column version of the submodels involved; model results are presented in Sect. 4, including column calculations for test cases and regional case studies in Sect. 4.1 and global results in Sect. 4.2; and we conclude with Sect. 5.

\section{Aerosol mixing states}

In the presence of multiple aerosol components it becomes challenging to compute the optical parameters of the aerosol. The main characteristics of the scattering and absorption process can be simulated using three parameters: the extinction coefficient $\sigma$, which is directly linked to the aerosol optical thickness $\tau$; the single-scattering albedo $\omega$ and the asymmetry parameter $g$. 
$\tau=\int \sigma \mathrm{d} z$

$\omega=\frac{\sigma_{\mathrm{s}}}{\sigma}$

$g=\frac{1}{2} \int_{-1}^{1} \mu P(\mu) \mathrm{d} \mu$

where $z$ denotes the vertical coordinate, $\sigma_{\mathrm{s}}$ the scattering part of the extinction coefficient, $\mu$ the cosine of the scattering angle and $P$ the phase function. For a given extinction coefficient $\sigma$, the fraction of absorbed radiation $1-\omega$ is proportional to the absorption efficiency. Assuming spherical particles, if there is only one component, these parameters can be computed straightforwardly using Mie theory and the corresponding refractive index of the component. However, if more than one component is involved, certain assumptions about the mixing state have to be made. The mixing states can be classified as either external (Fig. 1a) or internal (Fig. 1b and c).

\subsection{External mixing}

In an external mixture, each aerosol particle consists of only one component; however, different particles may consist of different components (Fig. 1a). In this case, the extinction coefficients of all components add up to the total extinction

$\sigma=\sum_{i} \sigma_{i}$

where the index $i$ identifies the component. The same applies to the scattering coefficient $\sigma_{\mathrm{s}}$. The ratio of the scattering coefficient and the total extinction coefficient yields the singlescattering albedo,

$\omega=\frac{\sigma_{\mathrm{s}}}{\sigma}=\frac{\sum_{i} \sigma_{\mathrm{s}, i}}{\sum_{i} \sigma_{i}}=\frac{\sum_{i} \sigma_{i} \omega_{i}}{\sum_{i} \sigma_{i}}$.

The flux scattered with angle $\arccos (\mu)$ by component $i$ is proportional to $P_{i}(\mu) \sigma_{\mathrm{s}, i}$, so that the corresponding flux scattered by all components is proportional to

$\sum_{i} P_{i}(\mu) \sigma_{\mathrm{s}, i}=P(\mu) \sigma_{\mathrm{s}}$,

where $P$ is the combined phase function of which the first moment, according to Eq. (1), yields the asymmetry parameter of the mixture,

$g=\frac{1}{2} \int_{-1}^{1} \mu \frac{\sum_{i} P_{i}(\mu) \sigma_{\mathrm{s}, i}}{\sigma_{\mathrm{s}}} \mathrm{d} \mu=\frac{\sum_{i} \sigma_{i} \omega_{i} g_{i}}{\sum_{i} \sigma_{i} \omega_{i}}$

Once the three parameters $\sigma, \omega$ and $g$ have been calculated according to Eqs. (2)-(4), the radiative-transfer equation can be solved at the same level as for an aerosol with only one component.

\subsection{Internal mixing}

Internal mixing assumes that single aerosol particles consist of different components (Fig. 1b and c). The simplest variant of internal mixing is based on the assumption that the different components are well mixed and form a homogeneous mixture inside the particles (Fig. 1c). In this case, the problem boils down to computing the refractive index of the mixture. Homogeneous internal mixing is a very common assumption, and various mixing rules to compute the refractive index have been defined.

\subsubsection{Mixing rules}

The following mixing rules are utilised in this work (for additional details and rules see Chýlek et al., 1988):

1. Volume average refractive index mixing rule: the complex refractive index $m$ of the mixture is computed as an average of the indices $m_{i}$ of the components, weighted with their volume fraction $v_{i}$;

$m=\sum_{i} v_{i} m_{i}$

2. Volume average dielectric constant mixing rule: the complex dielectric constant $\varepsilon=m^{2}$ of the mixture is computed as an average of the constants $\varepsilon_{i}$ of the components, weighted with their volume fraction $v_{i}$;

$\varepsilon=\sum_{i} v_{i} \varepsilon_{i}$

3. Maxwell Garnett mixing rule (Garnett, 1904): the ansatz for the equation for the complex dielectric constant considers tiny inclusions embedded within a matrix of component M. Averaging the electric field over many inclusions yields the effective dielectric constant;

$\varepsilon=\varepsilon_{M}\left(1+\frac{3 \sum_{i} v_{i} \frac{\varepsilon_{i}-\varepsilon_{\mathrm{M}}}{\varepsilon_{i}+2 \varepsilon_{\mathrm{M}}}}{1-\sum_{i} v_{i} \frac{\varepsilon_{i}-\varepsilon_{\mathrm{M}}}{\varepsilon_{i}+2 \varepsilon_{\mathrm{M}}}}\right)$

Note that despite the spatially inhomogeneous ansatz, using this limit also implies homogeneously mixed aerosol particles.

The refractive index resulting from these mixing rules can be used as input for a Mie computation to obtain the extinction coefficient $\sigma$, single-scattering albedo $\omega$ and asymmetry parameter $g$.

A mixture of strongly and weakly absorbing components generally absorbs more strongly when it is well mixed internally instead of externally mixed, as the larger cross section affected by the strong absorber in an internal mixture overcompensates the effect of a reduced imaginary part of the refractive index. 


\subsubsection{Core-shell particles}

Both the external and homogeneous internal mixture are highly idealised models of the atmospheric aerosol. In reality, we can assume that different aerosol components will neither coexist unaffected by each other, nor will they accumulate to homogeneous particles, but will more likely form coated particles in the atmosphere. Extensions of the Mie calculation to coated spheres and multilayered spheres are presented in Toon and Ackerman (1981); Bohren and Huffman (2007) and Yang (2003).

The shell layers (including the core) themselves may consist of different, well-mixed components. In this case, a mixing rule is used to compute the complex refractive index of each layer, which then serves as input for the core-shell calculation.

In many cases, the calculations of aerosol optical properties for core-shell particles are limited by the results for external and homogeneous internal mixing (Jacobson, 2000). Core-shell particles with a strongly absorbing core coated by a weak absorber generally absorb more sunlight than an external mixture of the same components. This is due to amplification by the shell, which effectively increases the cross section of the core. The amplification effect can result in absorption that is even stronger than that of a well-mixed internal mixture of the same components, depending on the Mie size parameter under consideration.

\subsubsection{Non-spherical particles}

Even though multilayered particle models can represent atmospheric aerosol particles more realistically than homogeneous spheres, common implementations still assume spherical symmetry. While this approximation is well defined as changing the order of averaging over many particles and computing the optical properties, it is generally not well motivated physically but rather used for computational simplicity.

In reality, dust particles can have irregular shapes which may be better represented by spheroids, ellipsoids or even more complex structures, possibly yielding, for the same particle volume, a higher optical thickness and single-scattering albedo (Kalashnikova and Sokolik, 2004; Colarco et al., 2014). Soot is known to form a variety of shapes by aggregating into fractal-like chains (Adachi et al., 2010; Scarnato et al., 2013). Even if liquid components lead to a spherical particle surface, embedded solid components are not necessarily distributed concentrically within the particle, and the exact position affects the optical properties (Fuller et al., 1999; Adachi et al., 2010).

The implementation of more detailed particle models becomes increasingly important as the overall precision of global climate models is improving. Introducing nonspherical particles into EMAC remains the subject of future work.

\section{Aerosol optical properties in EMAC}

The model setup used in this work involves three submodels in the computation of the aerosol radiative effect: GMXe (Global Modal-aerosol eXtension), AEROPT and RAD4ALL. The aerosol model GMXe (Pringle et al., 2010a, b) provides aerosol concentrations serving as input for AEROPT (Lauer et al., 2007; Pozzer et al., 2012), which computes the aerosol optical properties. These are then accounted for by RAD4ALL (Jöckel et al., 2006) when solving the radiative-transfer equation and computing heating rates.

For each cell of the grid representing the atmosphere and every RAD4ALL wavelength band, AEROPT computes the aerosol optical thickness $\tau$, the single-scattering albedo $\omega$ and the asymmetry parameter $g$. To do so, AEROPT combines data for six aerosol modes: the Aitken, accumulation and coarse modes, all of which are treated separately for hydrophilic and hydrophobic components. The nucleation mode additionally accounted for by GMXe is neglected in AEROPT due to its insignificant impact on the radiative transfer. Besides combining the modes, AEROPT integrates the different components in each mode as well as four subbands per RAD4ALL shortwave band (cf. Fig. S1 in the Supplement).

Aerosols from different modes are considered externally mixed, which is justified by the relatively small overlap of the mode size distributions. In contrast, within each mode, the aerosol components in the standard AEROPT version are assumed to be internally mixed and the volume average refractive index mixing rule Eq. (5) is used.

In this work we use a modified version of AEROPT in which we have additionally implemented the volume average dielectric constant mixing rule Eq. (6) and the Maxwell Garnett mixing rule Eq. (7). Our code provides the option of using external mixing also within each mode. Moreover, we have substituted the Mie code used by standard AEROPT, the Bohren and Huffman Mie subroutine (BHMIE; Bohren and Huffman, 2007) as implemented in the libRadtran (library for radiative transfer) package (Mayer and Kylling, 2005), with SCATTNLAY (Peña and Pal, 2009). The latter computes the scattering functions also for coated spheres with multiple layers of coating according to Yang (2003). SCATTNLAY allows the use of a large number of shells so that it essentially covers the most general case of spherical symmetric particles. Configured to perform standard AEROPT mixing, our mixing algorithm is equivalent to that of AEROPT 2.0 in MESSy version 2.42 (Jöckel et al., 2010).

To perform regional sensitivity studies and to easily test new mixing states and other developments in the EMAC aerosol and radiation code, we have implemented a column model which calls the original EMAC subroutines to compute aerosol optical properties, radiative fluxes and heating rates for a vertical column of the atmosphere. The computational resources required for the column model are modest so that it can run on a common PC. Once implemented and 
tested in the column model, new features are immediately available for global model simulations.

\section{Model results}

\subsection{Column model}

\subsubsection{Test cases}

To evaluate the functionality of the extended AEROPT code and to obtain a qualitative understanding of the optical properties of core-shell particles, we use the column model to consider two test cases.

Large differences in aerosol absorption for internal and external mixtures have been reported (Bohren and Huffman, 2007; Jacobson, 2000). Bohren and Huffman (2007) use an analytic approximation to illustrate that an internal mixture of a "black" and a "white" component can absorb more than twice as efficiently as an external mixture. As a benchmark for our extended AEROPT code, we provide the column model with the input used by Bohren and Huffman: for the black component the refractive index $m=1.7+i 0.7$ is used; for the white component $m=1.55+i 10^{-6}$. The volume mixing ratio of the black component is assumed to be $1 \%$. The particle radius is varied; however, in the case of the external mixture, the black particle radius is fixed at $0.05 \mu \mathrm{m}$.

Figure 2 shows the consistency of the single-scattering albedo computed with AEROPT and the results of Bohren and Huffman (2007). The smallest radii plotted are just below the validity limit of the analytic approximation which does not reproduce the drop in the single-scattering albedo for very small radii. Over the full range of radii, well-mixed particles absorb much more efficiently than externally mixed particles. Only for small particles is this efficiency exceeded by core-shell particles, which, for intermediate radii, yield results between the well- and externally mixed results. With increasing radius, the single-scattering albedo of the external mixture is increasingly dominated by the black particles because, due to their constant radius, their total cross section remains constant, whereas it decreases for the white particles. As a result, the single-scattering albedo becomes smaller than that of core-shell particles, which would not be the case if equal radii for black and white particles had been assumed.

Figure 2 includes results obtained considering particles with sizes distributed according to a log-normal distribution with geometric standard deviation $\sigma_{\mathrm{g}}=1.59$, using the average mass particle radius for the abscissa and, accordingly, an average mass particle radius of $0.05 \mu \mathrm{m}$ for black particles in the external mixture. Employing modes instead of single size particles has the side effect of smoothing the small-scale variations of the results. As in the full EMAC computation, in the following test case, we exclusively consider log-normal modes.

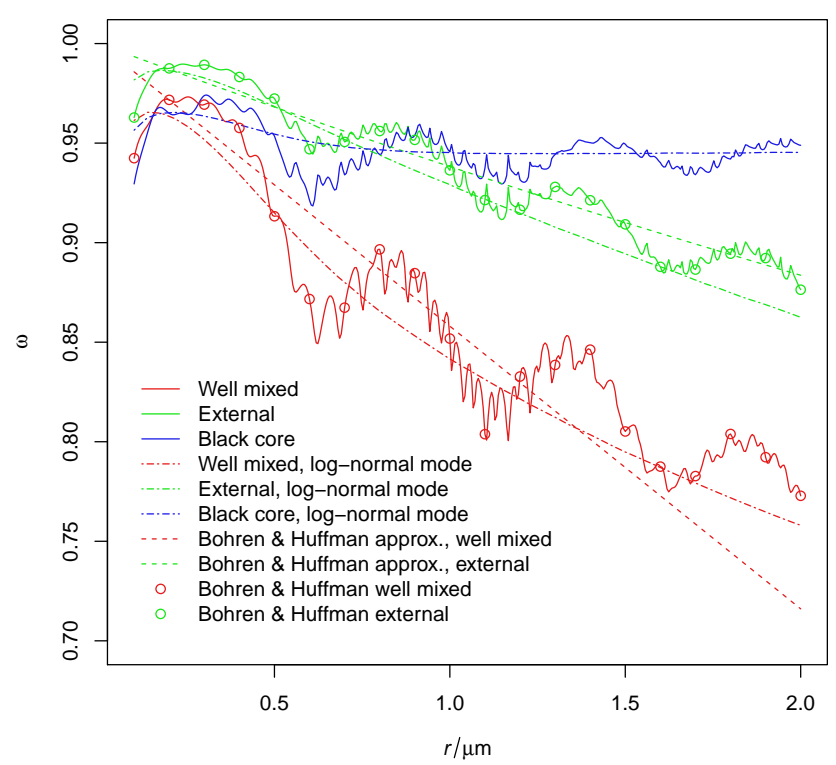

Figure 2. The single-scattering albedo of a mixture of a "black" component $(m=1.7+i 0.7,1 \%$ of the particle volume) and a "white" component ( $m=1.55+i 10^{-6}, 99 \%$ of the particle volume), assuming homogeneous internal mixing (red), external mixing (green) and core-shell particles (blue). The abscissa denotes the radius of the internally mixed particles and, in the case of the external mixture, the white particles; the radius of the black particles is $0.05 \mu \mathrm{m}$. The results have been calculated using our new SCATTNLAY-based AEROPT mixing algorithm for single size particles (solid) and log-normal size distributions $\left(\sigma_{\mathrm{g}}=1.59\right.$, dashdotted). In the latter case, average mass radii are used. Also shown are analytic approximations (dashed) and numeric results (circles) from Bohren and Huffman (2007) for homogeneous internal and external mixtures. The wavelength is $0.55 \mu \mathrm{m}$.

For large particles (Mie size parameter $x=2 \pi r / \lambda \gg 1$ ), core-shell particles typically absorb less efficiently than internally mixed particles (though more efficiently than externally mixed particles of the same size). However, in the Mie regime $(x \approx 1)$ this is not true in general, as can be seen from the leftmost part of Fig. 2 and more clearly in the test case shown in Fig. 3 (see also Fuller et al., 1999). The singlescattering albedo is shown for a mixture of two components: one with refractive index $m=1.75+i 0.43$ ("black") and resembling black carbon, and the second with refractive in$\operatorname{dex} m=1.5+i 0.02$ ("white") and resembling a mixture of various scattering components typically found in the atmosphere. The black component is assumed to account for $2 \%$ of the aerosol particle volume, the particle size is distributed according to a log-normal distribution with geometric standard deviation $\sigma_{\mathrm{g}}=1.59$, and the same median radius is used for all mixing states. For size parameters $x \lesssim 5$ the result for core-shell particles with a black core is very similar to that for well-mixed particles with a slightly smaller single-scattering albedo for size parameters $x \lesssim 2$. Since atmospheric aerosol size parameters both above and below the 


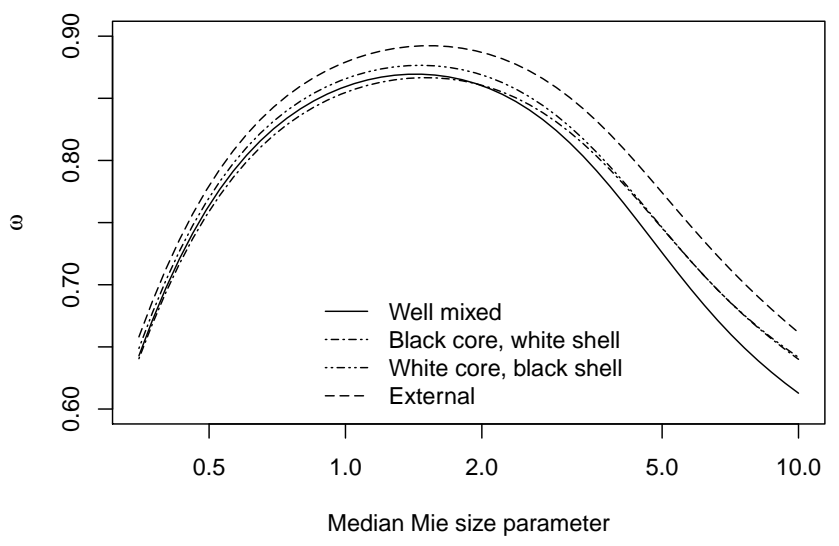

Figure 3. Single-scattering albedo of a mixture of $2 \%$ strongly absorbing matter with refractive index $m=1.75+i 0.43$ and $98 \%$ less absorbing material with $m=1.5+i 0.02$. The particle radius is distributed according to a log-normal mode with geometric standard deviation $\sigma_{\mathrm{g}}=1.59$. Over the entire median Mie size parameter range, the internal mixtures with well-mixed (volume average refractive index mixing rule) and core-shell particles absorb more efficiently than the external mixture. Depending on the median Mie size parameter $x_{\text {median }}$, absorption by core-shell particles with a black core is more $\left(x_{\text {median }} \lesssim 2\right)$ or less $\left(x_{\text {median }} \gtrsim 2\right)$ efficient than by well-mixed particles. For all mixing states, left and right of the maximum, the single-scattering albedo is very sensitive to the median Mie size parameter. Black coated spheres yield values between the result for internal and external mixing.

intersection are relevant, only a full evaluation of all aerosol modes and wavelength bands can reveal which mixing state absorbs more efficiently. Less ambiguous is the comparison of well-mixed to black coated spheres: in this example, even for small size parameters, the single-scattering albedo of black-coated particles is larger. A comparison of blackcore and black-shell particles can also be found in Hong et al. (2008), from whom selected results have been re-evaluated with our code, yielding good agreement.

Also apparent from Fig. 3 is the strong dependence of the single-scattering albedo on the aerosol mode median Mie size parameter. Left and right of the curves' maximum, changes in the Mie size parameter, e.g. due to water uptake, can alter the single-scattering albedo more drastically than changing the mixing state.

Figures 4 and 5 show that, qualitatively, the result in Fig. 3 also applies if the mixing ratio and standard deviation are varied. The relative difference of absorption efficiency for wellmixed and core-shell particles, $\left(\omega_{\text {well mixed }}-\omega_{\text {core shell }}\right) /(1-$ $\omega_{\text {well mixed }}$ ), is shown for black-core particles (Fig. 4) and black-coated particles (Fig. 5). Only the location of the intersection in the former case and the value of the difference plotted in both cases varies. For a fixed geometric standard deviation of $\sigma_{\mathrm{g}}=1.59$ (left panels), depending on the Mie size parameter and the black volume fraction, black-core particles can absorb $16 \%$ less or $8 \%$ more efficiently than well-mixed

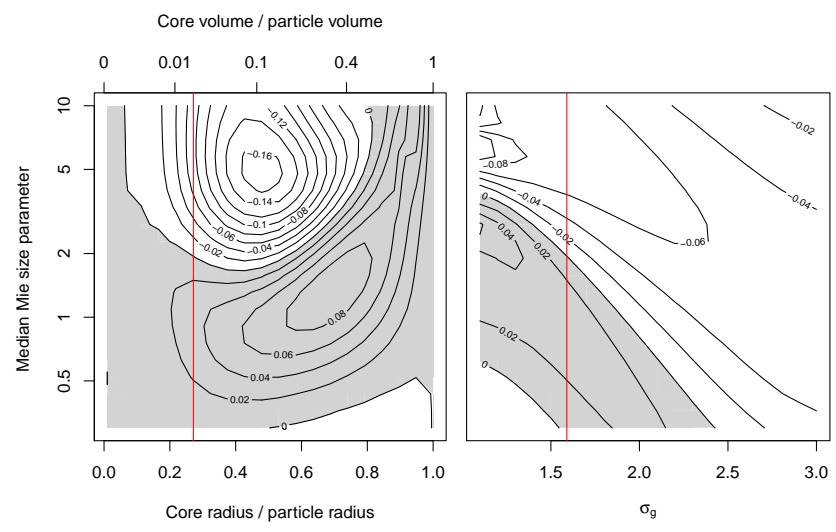

Figure 4. Relative difference of the absorption efficiency for well-mixed and core-shell particles $\left(\omega_{\text {well mixed }}-\omega_{\text {core shell }}\right) /(1-$ $\left.\omega_{\text {well mixed }}\right)$. The same components as in Fig. 3 are considered where the stronger absorbing component forms the core. In the left panel, the geometric standard deviation $\sigma_{\mathrm{g}}=1.59$ is used, whereas the mixing ratio is varied. In the right panel, the standard deviation $\sigma_{\mathrm{g}}$ is varied and the mixing ratio is the same as in Fig. 3. The solid red line in the left panel marks the mixing ratio used in the right panel; the solid red line in the right panel marks the standard deviation used in the left panel. For well-mixed particles, the volume average refractive index mixing rule is used.

particles. Black coated particles, the absorption of which in this example never exceeds that of well-mixed particles, can absorb up to almost $20 \%$ less efficiently than the homogeneously mixed particles.

The refractive index $m=1.75+i 0.43$ of the black component corresponds to the black-carbon value (at $600 \mathrm{~nm}$ wavelength) in the OPAC (Optical Properties of Aerosols and Clouds) 3.1 database (Hess et al., 1998) which is used by EMAC. In the literature, larger values for both the real and the imaginary part have been suggested (Bond and Bergstrom, 2006). As Fig. 6 shows, the above results change mostly quantitatively when changing the refractive indices. However, increasing the imaginary part of the refractive index for the black particles reduces the Mie size parameter range where core-shell particles absorb more efficiently than well-mixed particles. Consequently, in a full radiative transfer computation considering many different Mie size parameters it cancels the effect of the remaining parameter range to a lesser extent, decreasing the absorption efficiency of coreshell particles relative to that of well-mixed particles.

Different mixing ratios, refractive indices, median Mie size parameters, mode widths and wavelengths are relevant to the single-scattering albedo in the atmosphere. Consequently, more elaborate case studies are required to extend our reasoning to atmospheric aerosols, which will be addressed in the following section. 


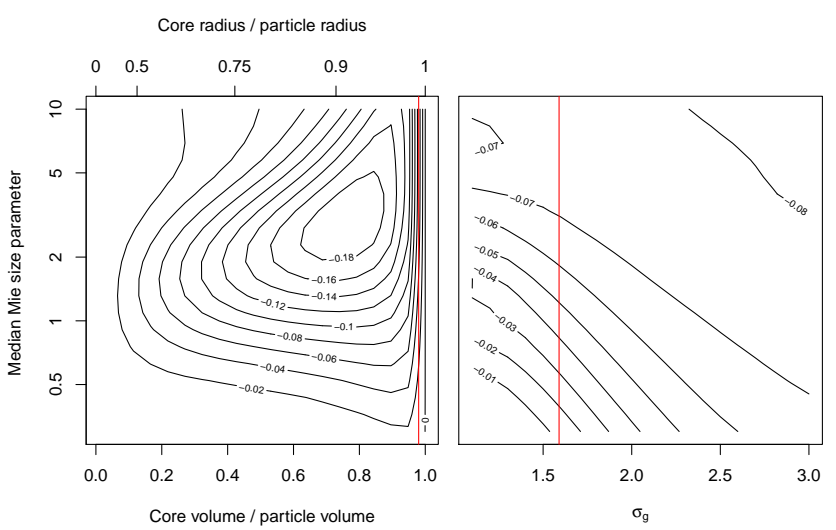

Figure 5. Same as Fig. 4 but with the stronger absorbing component coating the less absorbing component.

\subsubsection{Regional sensitivity studies}

To study regional mixing-state sensitivity under realistic conditions, we employ the column model and introduce aerosol concentrations from a global simulation for the year 2005 using the same model setup as Pozzer et al. (2012), which is also used in Sect. 4.2. For each region, we consider days on which the corresponding column is cloud free at noon local time. The concentrations and additional data required for the flux and heating rate computations are taken from the model time step with the smallest zenith angle. The radiative flux is evaluated every $18 \mathrm{~min}$ so that all case studies are performed within 9 min of solar noon. The geometric standard deviation of the hydrophilic and hydrophobic coarse mode are $\sigma_{\mathrm{g}}=2.2$ and $\sigma_{\mathrm{g}}=2$, respectively, and $\sigma_{\mathrm{g}}=1.59$ for all other modes.

The refractive indices are taken from the OPAC 3.1 database (Hess et al., 1998) (black carbon, mineral dust) and HITRAN 2004 (high-resolution transmission molecular absorption database) (Rothman et al., 2005) (organic carbon, sea salt, ammonium sulfate, water). The mineral dust and organic-carbon values have been complemented by data from I. N. Sokolik (unpublished data) and Kirchstetter et al. (2004), respectively. The data for ammonium sulfate also serve as default for other water-soluble components. The indices are plotted in Fig. S1; the numerical values can be found in Table S1 (real part $n$ ) and Table S2 (imaginary part $\kappa)$ in the Supplement.

\section{Northern China}

The high aerosol concentrations and abundance of aerosol components make the coastal areas in northern China particularly interesting for studying mixing-state sensitivity. One may assume that, especially close to the sources, aerosols are not homogeneously mixed. We focus on a model column centred at $38.7^{\circ} \mathrm{N}, 117.0^{\circ} \mathrm{E}$, adjacent to Bohai Bay southeast of Beijing in October. For the given model resolution, this column covers the area between $38.1^{\circ} \mathrm{N}, 116.4^{\circ} \mathrm{E}$ and
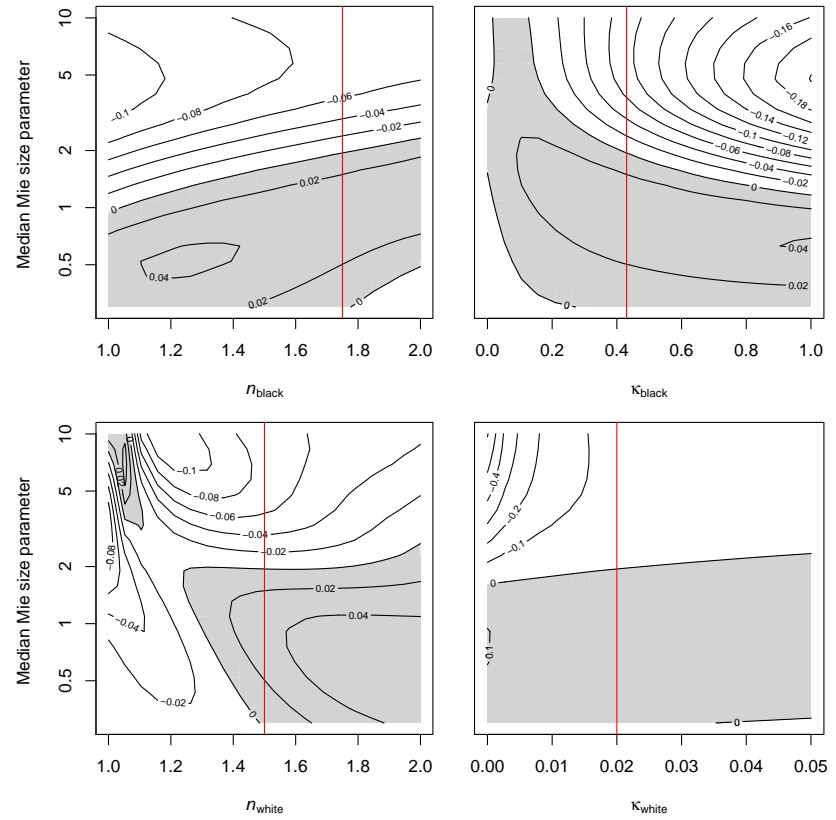

Figure 6. Relative difference of the absorption efficiency for wellmixed and core-shell particles as in Fig. 4 for the geometric standard deviation $\sigma_{\mathrm{g}}=1.59,2 \%$ black volume and varying refractive indices $m_{\text {black }}=n_{\text {black }}+i \kappa_{\text {black }}$ and $m_{\text {white }}=n_{\text {white }}+i \kappa_{\text {white }}$. The solid red lines mark the refractive indices used in the previous figures. For well-mixed particles, the volume average refractive index mixing rule is used.

$39.3^{\circ} \mathrm{N}, 117.6^{\circ} \mathrm{E}$ (see inset in Fig. 7). The vertical profiles of the concentrations in each mode are shown in Fig. 7. In particular in the accumulation mode, which is the most relevant for solar radiation scattering, the concentrations are high, and various components are accompanied by a small but significant fraction of black carbon.

The resulting optical properties, radiative flux and temperature tendency are shown in Fig. 8. In the leftmost panel, the aerosol optical depth (AOD) $\tau$ is shown for internal mixing using the average refractive index, external mixing and an intermediate mixing state in which only black carbon is externally mixed with an internal mixture of the remaining components. Also shown are the results for particles with a black-carbon core or shell where the rest of the components are well mixed using the average refractive index. The sensitivity to the mixing state appears to be small.

The RAD4ALL shortwave band covering the lower end of the solar wavelength spectrum $(0.25-0.69 \mu \mathrm{m})$ dominates not only because it accounts for almost $50 \%$ of the incoming energy but also because the corresponding aerosol optical depth is largest. For clarity, the single-scattering albedo in the second panel is shown for this band only. In contrast to the optical depth, the single-scattering albedo of the internal mixture differs significantly from that of the external mixture. This is primarily related to the black-carbon component as can be seen from the intermediate mixing state (dashed line): even 


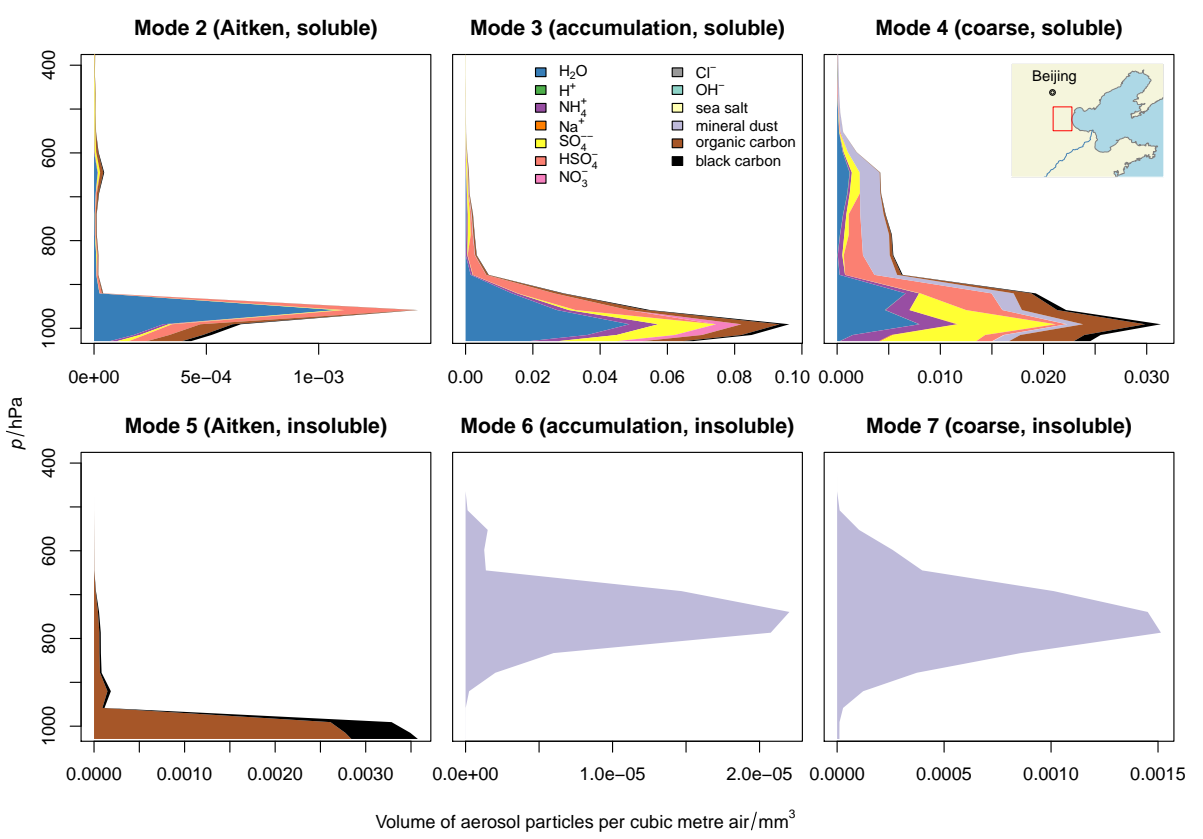

Figure 7. Vertical profiles of the aerosol concentrations in six modes over China which have been used as input for the column model when computing the optical properties in Fig. 8. The red rectangle in the inset of the top right figure depicts the area covered by the model column.
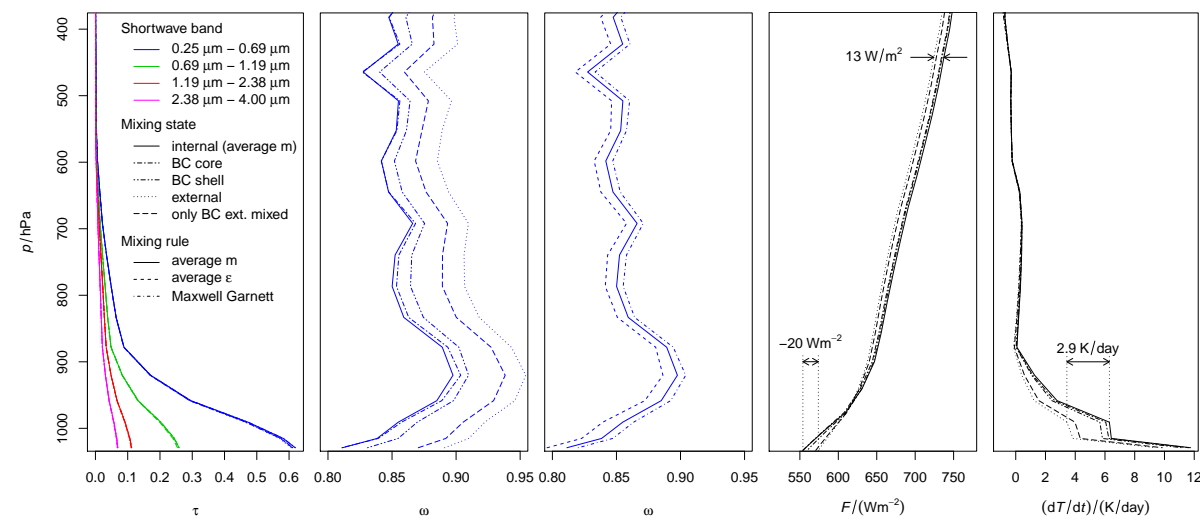

Figure 8. Column model results over China. From left to right: aerosol optical depth $\tau$, single-scattering albedo $\omega$, single-scattering albedo (alternative mixing rules), net shortwave flux $F$, temperature tendency $\mathrm{d} T / \mathrm{d} t$. The optical depth is shown for each shortwave band, whereas the single-scattering albedo is shown only for the dominant band $(0.25-0.69 \mu \mathrm{m})$. The flux takes all solar bands into account; in addition, the temperature tendency takes the effects of terrestrial infrared radiation into account.

though only black carbon is externally mixed, we compute an effect comparable to that for the external mixture. This is even more remarkable considering the fact that the volume of the black-carbon particles accounts for only a small fraction of the total particle volume as illustrated in Fig. 7. Assuming that black carbon forms the core of the aerosol particles yields a single-scattering albedo only marginally larger than the result for well-mixed particles. In contrast, assuming black carbon to coat the rest of the components results in significantly less absorption.

The difference between single-scattering albedo for internal and external mixing is much more evident than that between the different variants of homogeneous internal mixing in the centre panel, namely the average refractive index mixing rule, the average dielectric constant mixing rule and the Maxwell Garnett mixing rule. For the latter we consider water as a matrix (black and organic carbon in the insoluble Aitken mode are well mixed using the average refractive index; in the other two dry, insoluble modes there is only one component). It yields slightly less absorption than the average refractive index mixing rule. In contrast, the average dielectric constant mixing rule yields stronger absorption and deviates more strongly from the result obtained using the average refractive index mixing rule. The difference 


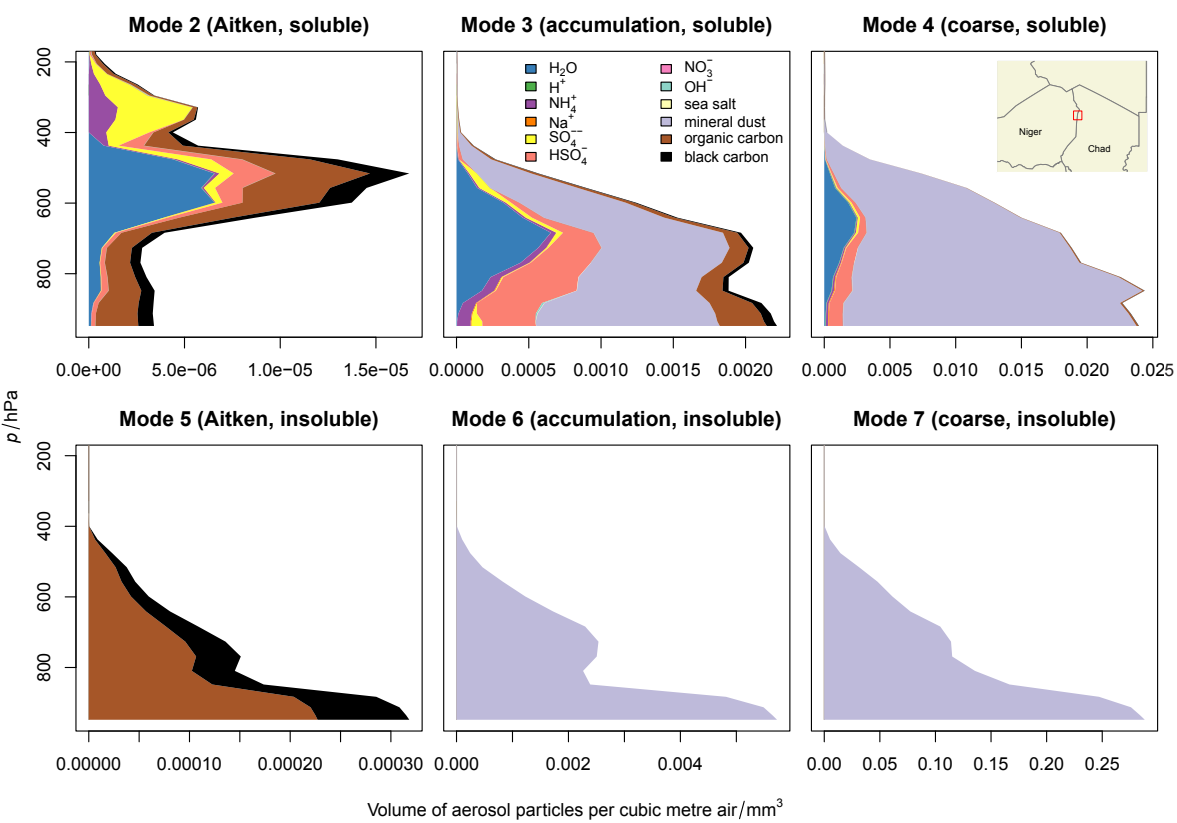

Figure 9. Vertical profiles of the aerosol concentrations in six modes over the Sahara which have been used as input for the column model when computing the optical properties in Fig. 10. The red rectangle in the inset of the top right figure depicts the area covered by the model column.

is comparable to that for black-carbon-coated particles, but has the opposite sign. We conclude that it is highly relevant to correctly apply internal or external mixing. The results are less, but still significantly, sensitive to the choice of the internal mixing state (well mixed or core shell) and the mixing rule, which are both about equally relevant.

The lower single-scattering albedo of the internal mixtures is reflected by the radiative-flux profile in the fourth panel. The stronger absorption in the atmosphere leads to a larger net downward shortwave flux at the top of the atmosphere, whereas this flux is reduced at the bottom of the atmosphere. In this example, switching from external to internal mixing alters the flux by $13 \mathrm{~W} \mathrm{~m}^{-2}$ at the top of the atmosphere and $-20 \mathrm{~W} \mathrm{~m}^{-2}$ at the surface, whereas the longwave flux is essentially unaffected. As a consequence, for internal mixing an additional $33 \mathrm{~W} \mathrm{~m}^{-2}$ are absorbed within the troposphere. This increases the heating rate within the troposphere, as shown in the rightmost panel. Here, internal mixing yields an additional contribution to the heating of the lower troposphere at noon of up to $2.9 \mathrm{~K} \mathrm{day}^{-1}$.

The two main effects of increasing aerosol absorption are shown by the two right-hand profiles. Firstly, the stronger heating of the troposphere impacts the regional dynamics of the atmosphere. Secondly, the increased downward flux at the top of the atmosphere increases the warming. We will quantify this effect on larger scales in Sect. 4.2.

\section{Sahara}

The exceptionally high aerosol concentrations found over northern Africa are dominated by Saharan mineral dust. Consequently, despite a strong aerosol radiative effect, we expect a small mixing-state sensitivity. Figure 9 shows the aerosol concentrations in a column over the Niger-Chad border (centred at $19.63^{\circ} \mathrm{N}, 15.75^{\circ} \mathrm{E}$; see inset in Fig. 9) at the end of June. By far the highest concentration is found in the hydrophobic coarse mode, exclusively represented by mineral dust.

This dominance of large aerosol particles is reflected by an almost negligibly small wavelength dependence of the aerosol optical depth, shown in Fig. 10, and, correspondingly, a small Ångström exponent. Thus, larger wavelengths are more strongly affected by extinction than in the previous example, and, therefore, the single-scattering albedo is shown for all shortwave bands. Like the optical depth, the singlescattering albedo shows very little sensitivity to the mixing state. The minor sensitivity, which mostly occurs at high altitudes where the dust concentration vanishes, does not appear in the flux profile and the heating rate.

\section{Sichuan Basin, Gangetic Plain, eastern Niger Delta}

Figure 11 combines results for three regions with high sensitivity to the aerosol mixing state: over the Sichuan Basin in southwestern China aerosol compositions are similar to that over the coastal areas in northern China but with even higher concentrations; the Gangetic Plain shows a larger fraction of 


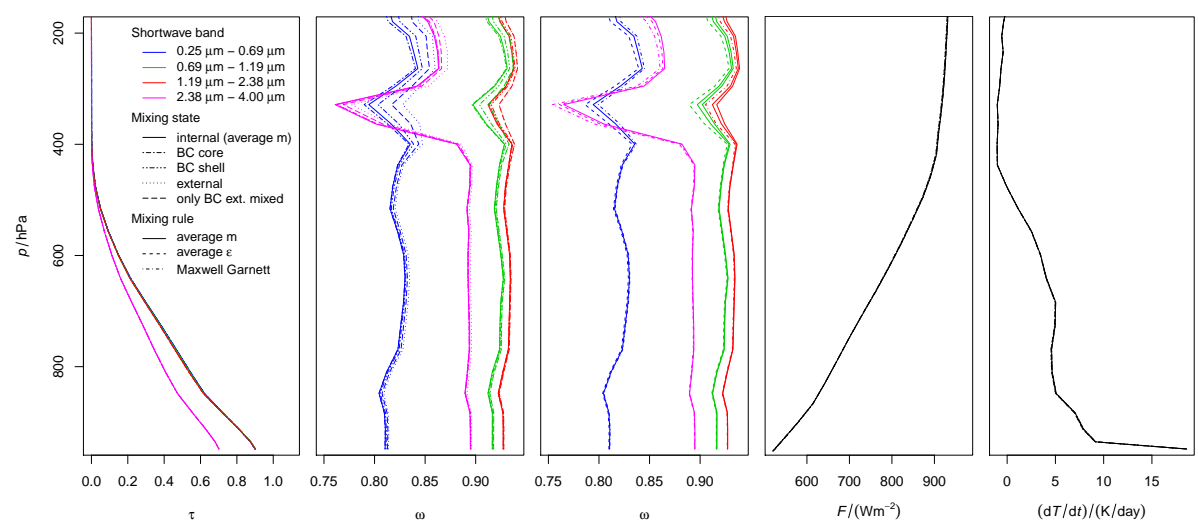

Figure 10. Column model results over the Sahara. From left to right: aerosol optical depth $\tau$, single-scattering albedo $\omega$, single-scattering albedo (alternative mixing rules), net shortwave flux $F$, temperature tendency $\mathrm{d} T / \mathrm{d} t$. The temperature tendency takes the terrestrial bands into account. In this example, the mixing-state sensitivity is small so that the flux profiles and the temperature tendencies for the different mixing states coincide.

organic carbon; and in the eastern Niger Delta black and organic carbon are combined with large amounts of mineral dust.

As in the northern-China example, the single-scattering albedo for particles with a black-carbon core is very close to that for homogeneously internally mixed particles. It can be both slightly smaller and larger, similar to the result in Fig. 3. In contrast, absorption by particles coated with black carbon is always smaller than by well-mixed particles. The single-scattering albedo over the eastern Niger Delta, for example, shows that the difference can be almost half as large as that between the result for externally mixed black carbon and well-mixed particles. While spherical symmetric coating of particles by black carbon is unlikely to be found in reality, black-carbon inclusions at the edge of aerosol particles have been observed (Adachi et al., 2010) and made responsible for reduced absorption enhancement in internal mixtures (Cappa et al., 2012). Typically, the specific absorption tends to decrease if the black carbon is further away from the particle centre and closer to the surface (Fuller et al., 1999). Small differences between the radiative forcing of well-mixed and black-carbon core particles have been reported previously (Kim et al., 2008), and larger differences, found by Jacobson (2001), might be attributed to a different black-carbon refractive index and particle size distribution.

Generally, the sensitivity of the shortwave flux at the surface is higher than at the TOA (top of the atmosphere). This difference increases with decreasing single-scattering albedo. The more strongly absorbing the aerosol, the less the scattered radiation that reaches the TOA, decreasing the sensitivity of the TOA flux. In addition, the sensitivity at the surface is higher with a larger total amount of absorbed radiation, i.e. a smaller single-scattering albedo. Over the eastern Niger Delta, with a relatively low single-scattering albedo of about 0.7 , the surface flux for internal and external mixing differs by $-25 \mathrm{~W} \mathrm{~m}^{-2}$, which is twice as large as the difference at the TOA $\left(12 \mathrm{~W} \mathrm{~m}^{-2}\right)$.

\subsection{Global sensitivity}

To estimate the mixing-state sensitivity of the global radiative forcing by aerosols, we simulate the year 2005 using the model version employed in Pozzer et al. (2012), where the setup is described extensively. In EMAC, the version MESSy 1.9 is utilised in combination with ECHAM 5.3.01 using the horizontal resolution $\mathrm{T} 106\left(\approx 1.1^{\circ} \times 1.1^{\circ}\right)$ and 31 vertical layers up to $10 \mathrm{hPa}$ in the lower stratosphere. The model dynamics are nudged to meteorological analyses of the European Centre for Medium-Range Weather Forecasts (ECMWF), and the prognostic radiative-transfer calculation uses the Tanre aerosol climatology (Tanre et al., 1984).

In each model time step, we call our modified AEROPT routine multiple times to compute the aerosol optical properties for different mixing states. Accordingly, we use multiple diagnostic calls to the radiation submodel RAD4ALL to evaluate the corresponding fluxes and heating rates, thereby obtaining instantaneous radiative forcings not including dynamical feedbacks.

Figure 12 compares the annual average of the shortwave fluxes for internal (int) and external (ext) mixing as well as the intermediate mixing state from Sect. 4.1.2, in which only black carbon is externally mixed (bcext).

The TOA forcing is affected by the mixing state most significantly over China and the Ganges-Brahmaputra-Meghna basin. Over China, the annual average of the difference between the TOA flux for internal and external mixing, $F_{\text {int }}-$ $F_{\text {ext }}$, reaches values in excess of $8 \mathrm{~W} \mathrm{~m}^{-2}$. While the sensitivity is largely correlated to the AOD as published in Pozzer et al. (2012), there are noticeable exceptions. Most strikingly, northern Africa shows very little sensitivity, whereas the AOD in that region is among the highest worldwide. As 

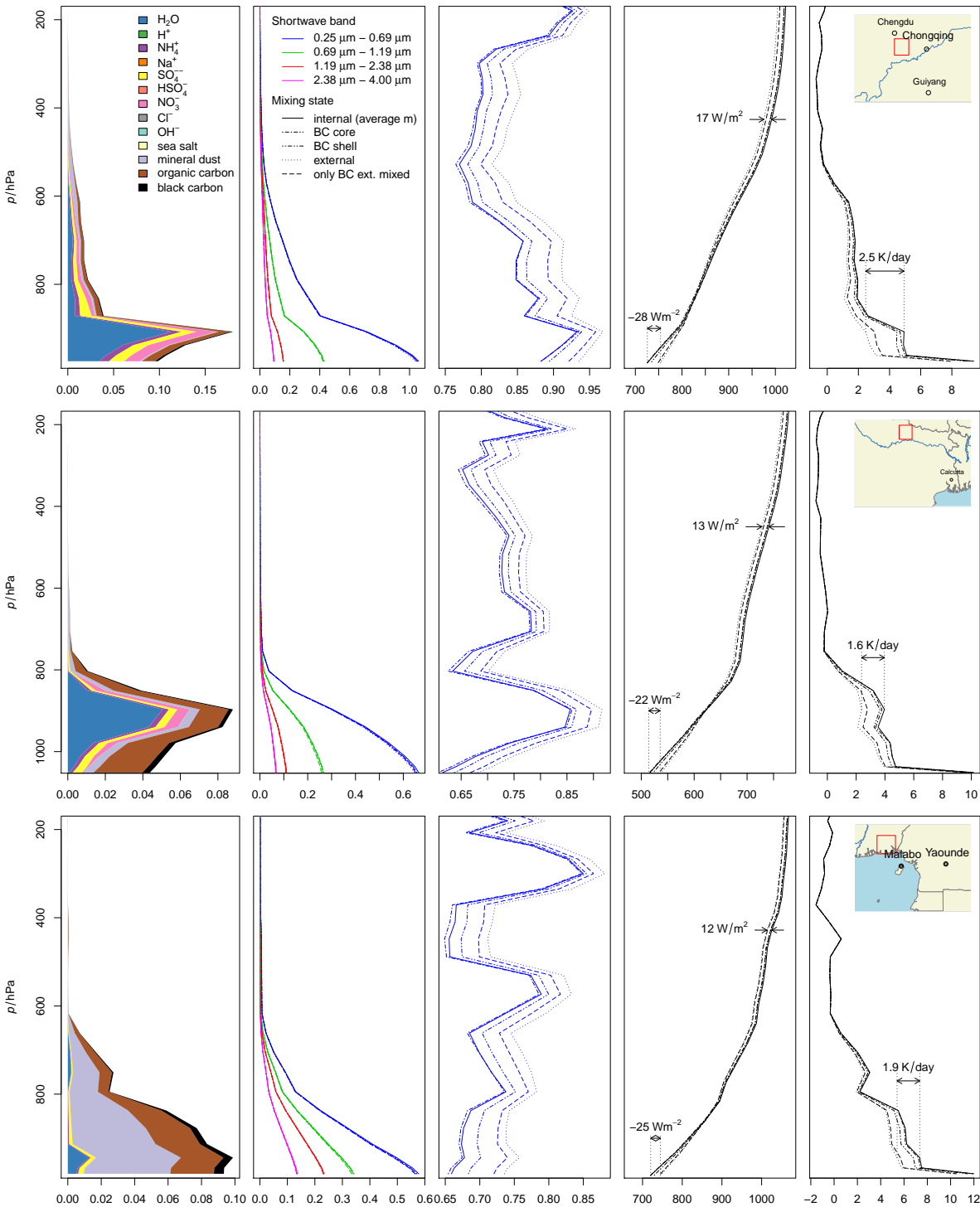

$\phi /\left(\mathrm{mm}^{3} / \mathrm{m}^{3}\right)$

$\tau$
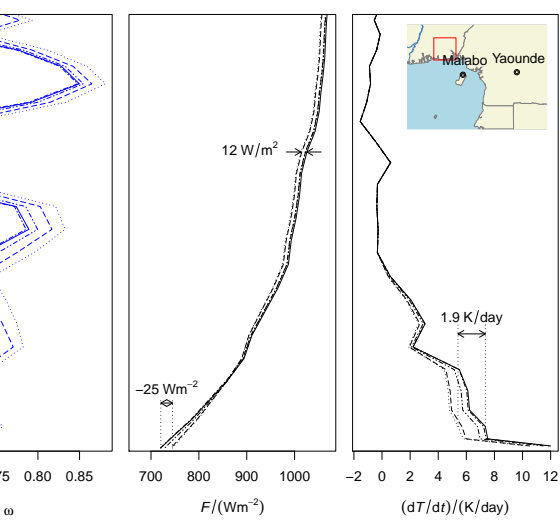

Figure 11. Column model results over (from top to bottom) the Sichuan Basin in China $\left(29.72^{\circ} \mathrm{N}, 104.62^{\circ} \mathrm{E}\right.$; April), the Gangetic Plain in India $\left(26.35^{\circ} \mathrm{N}, 84.37^{\circ} \mathrm{E}\right.$; November) and the eastern Niger Delta in Nigeria $\left(5.05^{\circ} \mathrm{N}, 7.87^{\circ} \mathrm{E}\right.$; January). From left to right: aerosol concentrations, aerosol optical depth $\tau$, single-scattering albedo $\omega$, net shortwave flux $F$, temperature tendency d $T / \mathrm{d} t$. The optical depth is shown for each shortwave band, whereas the single-scattering albedo is shown only for the dominant band $(0.25-0.69 \mu \mathrm{m})$. The flux takes all solar bands into account; in addition, the temperature tendency takes the effects of terrestrial infrared radiation into account.

demonstrated with the Saharan column in Sect. 4.1.2, the reason is that the AOD in northern Africa is dominated by mineral dust, while other aerosol components, including black carbon and thus aerosol mixing, play a minor role. The same applies to the Taklamakan Desert in northwest China. In central Africa, on the other hand, biomass burning aerosols are important and, again, the contribution by black carbon gives rise to a significant effect by the mixing state.

The change in TOA flux goes hand in hand with an even slightly larger difference in the surface flux with opposite sign. As the difference in flux absorbed by the atmosphere thus regionally exceeds $18 \mathrm{~W} \mathrm{~m}^{-2}$ on the annual average, we expect the regional atmospheric dynamics to be sensitive to alterations of the aerosol mixing scheme.

As in the regional case studies described in Sect. 4.1.2, the mixing-state sensitivity is mostly related to black carbon globally, too. The difference between the TOA flux for internal mixing and the intermediate mixing state $F_{\text {int }}-F_{\text {bcext }}$ shows, to a large extent, the same pattern as that between the flux for internal and external mixing. Even though the difference is smaller, black carbon generally accounts for more than half of the total effect, with the difference reaching 

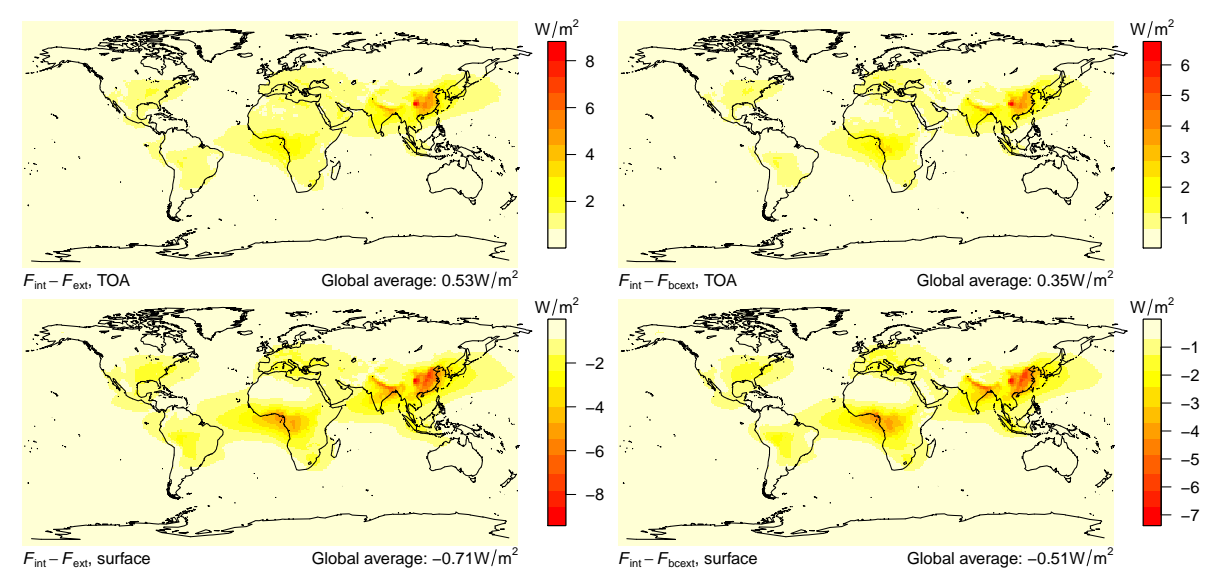

Figure 12. Difference in net shortwave flux between internal and external mixing $F_{\text {int }}-F_{\text {ext }}$ (top left) and between internal and intermediate mixing state $F_{\text {int }}-F_{\text {bcext }}$ (top right) at the top of the atmosphere, averaged over the year 2005. The bottom row shows the corresponding values at the surface.

$7 \mathrm{~W} \mathrm{~m}^{-2}$ over China. This is consistent with our results for the regional single-scattering albedos in Figs. 8 and 11.

The global average of the TOA shortwave flux difference amounts to $0.53 \mathrm{~W} \mathrm{~m}^{-2}$ when comparing the internal mixture to the fully external mixture and $0.35 \mathrm{~W} \mathrm{~m}^{-2}$ when comparing to the intermediate mixing state. Being of the same order of magnitude as current estimates for the aerosol direct radiative forcing, these values suggest a considerable mixing-state sensitivity of the global energy budget, in particular because it may be assumed that black carbon is predominantly of anthropogenic origin. This supports results of prior studies: the global average of $0.35 \mathrm{~W} \mathrm{~m}^{-2}$ is between that in Chung and Seinfeld (2005), where the difference of the forcing for the well-mixed internal mixture and the forcing for externally mixed elemental carbon is estimated at $0.27 \mathrm{~W} \mathrm{~m}^{-2}$, and Jacobson (2000), who estimated this to be $0.51 \mathrm{~W} \mathrm{~m}^{-2}$.

\section{Conclusions}

We have implemented revised aerosol mixing states in the EMAC submodel AEROPT to study the sensitivity for various types of particle components worldwide.

The regional case studies performed with a new column version of the EMAC radiation code as well as our global results reveal a significant sensitivity to a transition from external to internal mixing, which increases aerosol absorption by black carbon. The difference depends on the local concentrations of the aerosol components, which cannot be taken into account using a constant enhancement factor applied to the external mixing result. Our implementations of internal and external mixing yield results consistent with calculations by Bohren and Huffman (2007), and the strong sensitivity of the global radiative forcing to excluding black carbon from the otherwise internal aerosol mixture supports the findings by Jacobson (2000) and Chung and Seinfeld (2005).
In EMAC, the AEROPT submodel combines internal mixing within and external mixing between the modes calculated with the GMXe submodel, and, by allowing aerosol particles to advance from hydrophobic to hydrophilic modes, the model captures the effect of changing optical properties through chemical ageing, hygroscopic growth and coagulation. Our results underscore the importance of modelling these processes with the appropriate level of detail to adequately account for the aerosol radiative forcings and climate effects.

In our regional case studies, homogeneous internal mixing provides a good approximation for the optical properties of particles with a strongly absorbing core. However, it overestimates absorption by particles with strongly absorbing coating. Therefore, we recommend taking the inner structure of internally mixed particles into account.

\section{Code availability}

The Modular Earth Submodel System (MESSy) is continuously further developed and applied by a consortium of institutions. The usage of MESSy and access to the source code is licensed to all affiliates of institutions which are members of the MESSy Consortium. Institutions can be a member of the MESSy Consortium by signing the MESSy Memorandum of Understanding. More information can be found on the MESSy Consortium Website (http://www.messy-interface. org). The submodel AEROPT is part of MESSy. Regarding the column model and mixing rules used in this study but not yet included in released MESSy versions, the author Klaus Klingmüller (klingmueller@cyi.ac.cy) can be contacted directly.

The Supplement related to this article is available online at doi:10.5194/gmd-7-2503-2014-supplement. 
Acknowledgements. We thank Andrea Pozzer for providing the EMAC setup used in Sect. 4.2. The research leading to these results has received funding from the European Research Council under the European Union's Seventh Framework Programme (FP7/20072013)/ERC grant agreements no. 226144 and no. 261600.

Edited by: V. Grewe

\section{References}

Adachi, K., Chung, S. H., and Buseck, P. R.: Shapes of soot aerosol particles and implications for their effects on climate, J. Geophys. Res.-Atmos., 115, D15206, doi:10.1029/2009JD012868, 2010.

Bohren, C. F. and Huffman, D. R.: Absorption and Scattering of Light by Small Particles, Wiley-VCH Verlag GmbH, 2007.

Bond, T. C. and Bergstrom, R. W.: Light absorption by carbonaceous particles: an investigative review, Aerosol Sci. Tech., 40, 27-67, doi:10.1080/02786820500421521, 2006.

Bond, T. C., Doherty, S. J., Fahey, D. W., Forster, P. M., Berntsen, T., Deangelo, B. J., Flanner, M. G., Ghan, S., Kärcher, B., Koch, D., Kinne, S., Kondo, Y., Quinn, P. K., Sarofim, M. C., Schultz, M. G., Schulz, M., Venkataraman, C., Zhang, H., Zhang, S., Bellouin, N., Guttikunda, S. K., Hopke, P. K., Jacobson, M. Z., Kaiser, J. W., Klimont, Z., Lohmann, U., Schwarz, J. P., Shindell, D., Storelvmo, T., Warren, S. G., and Zender, C. S.: Bounding the role of black carbon in the climate system: a scientific assessment, J. Geophys. Res.Atmos., 118, 5380, doi:10.1002/jgrd.50171, 2013.

Cappa, C. D., Onasch, T. B., Massoli, P., Worsnop, D. R., Bates, T. S., Cross, E. S., Davidovits, P., Hakala, J., Hayden, K. L., Jobson, B. T., Kolesar, K. R., Lack, D. A., Lerner, B. M., Li, S.-M., Mellon, D., Nuaaman, I., Olfert, J. S., Petäjä, T., Quinn, P. K., Song, C., Subramanian, R., Williams, E. J., and Zaveri, R. A.: Radiative absorption enhancements due to the mixing state of atmospheric black carbon, Science, 337, 1078-1081, doi:10.1126/science.1223447, 2012.

Carslaw, K. S., Lee, L. A., Reddington, C. L., Pringle, K. J., Rap, A., Forster, P. M., Mann, G. W., Spracklen, D. V., Woodhouse, M. T., Regayre, L. A., and Pierce, J. R.: Large contribution of natural aerosols to uncertainty in indirect forcing, Nature, 503, 67-71, doi:10.1038/nature12674, 2013.

Chung, S. H. and Seinfeld, J. H.: Climate response of direct radiative forcing of anthropogenic black carbon, J. Geophys. Res.Atmos., 110, D11102, doi:10.1029/2004JD005441, 2005.

Chýlek, P., Srivastava, V., Pinnick, R. G., and Wang, R. T.: Scattering of electromagnetic waves by composite spherical particles: experiment and effective medium approximations, Appl. Optics, 27, 2396-2404, doi:10.1364/AO.27.002396, 1988.

Colarco, P. R., Nowottnick, E. P., Randles, C. A., Yi, B., Yang, P., Kim, K.-M., Smith, J. A., and Bardeen, C. G.: Impact of radiatively interactive dust aerosols in the NASA GEOS-5 climate model: Sensitivity to dust particle shape and refractive index, J. Geophys. Res.-Atmos., 119, 753-786, doi:10.1002/2013JD020046, 2014.

Easter, R. C., Ghan, S. J., Zhang, Y., Saylor, R. D., Chapman, E. G., Laulainen, N. S., Abdul-Razzak, H., Leung, L. R., Bian, X., and Zaveri, R. A.: MIRAGE: Model description and evaluation of aerosols and trace gases, J. Geophys. Res.-Atmos., 109, 20210, doi:10.1029/2004JD004571, 2004.
Fuller, K. A., Malm, W. C., and Kreidenweis, S. M.: Effects of mixing on extinction by carbonaceous particles, J. Geophys. Res.Atmos., 104, 15941, doi:10.1029/1998JD100069, 1999.

Garnett, J. C. M.: Colours in metal glasses and in metallic films, Philos. T. R. Soc. Lond., 203, 385-420, doi:10.1098/rsta.1904.0024, 1904.

Ghan, S. J., Liu, X., Easter, R. C., Zaveri, R., Rasch, P. J., Yoon, J.H., and Eaton, B.: Toward a minimal representation of aerosols in climate models: comparative decomposition of aerosol direct, semidirect, and indirect radiative forcing, J. Climate, 25, 64616476, doi:10.1175/JCLI-D-11-00650.1, 2012.

Hess, M., Koepke, P., and Schult, I.: Optical properties of aerosols and clouds: the software package OPAC, B. Am. Meteorol. Soc., 79, 831-844, doi:10.1175/15200477(1998)079<0831:OPOAAC>2.0.CO;2, 1998.

Hong, G., Feng, Q., Yang, P., Kattawar, G. W., Minnis, P., and $\mathrm{Hu}, \mathrm{Y}$. X.: Optical properties of ice particles in young contrails, J. Quant. Spectrosc. Ra., 109, 2635-2647, doi:10.1016/j.jqsrt.2008.06.005, 2008.

IPCC: Summary for policymakers, in: Climate Change 2013: The Physical Science Basis. Contribution of Working Group I to the Fourth Assessment Report of the Intergovernmental Panel on Climate Change, available at: http://www.ipcc.ch/report/ar5/ wg1/ (last access: 14 May 2014), 2013.

Jacobson, M. Z.: A physically-based treatment of elemental carbon optics: implications for global direct forcing of aerosols, Geophys. Res. Lett., 27, 217-220, doi:10.1029/1999GL010968, 2000.

Jacobson, M. Z.: Strong radiative heating due to the mixing state of black carbon in atmospheric aerosols, Nature, 409, 695-697, doi:10.1038/35055518, 2001.

Jöckel, P., Sander, R., Kerkweg, A., Tost, H., and Lelieveld, J.: Technical Note: The Modular Earth Submodel System (MESSy) - a new approach towards Earth System Modeling, Atmos. Chem. Phys., 5, 433-444, doi:10.5194/acp-5-433-2005, 2005.

Jöckel, P., Tost, H., Pozzer, A., Brühl, C., Buchholz, J., Ganzeveld, L., Hoor, P., Kerkweg, A., Lawrence, M. G., Sander, R., Steil, B., Stiller, G., Tanarhte, M., Taraborrelli, D., van Aardenne, J., and Lelieveld, J.: The atmospheric chemistry general circulation model ECHAM5/MESSy1: consistent simulation of ozone from the surface to the mesosphere, Atmos. Chem. Phys., 6, 5067-5104, doi:10.5194/acp-6-5067-2006, 2006.

Jöckel, P., Kerkweg, A., Pozzer, A., Sander, R., Tost, H., Riede, H., Baumgaertner, A., Gromov, S., and Kern, B.: Development cycle 2 of the Modular Earth Submodel System (MESSy2), Geosci. Model Dev., 3, 717-752, doi:10.5194/gmd-3-717-2010, 2010.

Kalashnikova, O. and Sokolik, I.: Modeling the radiative properties of nonspherical soil-derived mineral aerosols, J. Quant. Spectrosc. Ra., 87, 137-166, doi:10.1016/j.jqsrt.2003.12.026, 2004.

Kim, D., Wang, C., Ekman, A. M. L., Barth, M. C., and Rasch, P. J.: Distribution and direct radiative forcing of carbonaceous and sulfate aerosols in an interactive size-resolving aerosol-climate model, J. Geophys. Res.-Atmos., 113, 16309 , doi:10.1029/2007JD009756, 2008.

Kirchstetter, T. W., Novakov, T., and Hobbs, P. V.: Evidence that the spectral dependence of light absorption by aerosols is affected by organic carbon, J. Geophys. Res.-Atmos., 109, D21208, doi:10.1029/2004JD004999, 2004. 
Lauer, A., Eyring, V., Hendricks, J., Jöckel, P., and Lohmann, U.: Global model simulations of the impact of ocean-going ships on aerosols, clouds, and the radiation budget, Atmos. Chem. Phys., 7, 5061-5079, doi:10.5194/acp-7-5061-2007, 2007.

Mayer, B. and Kylling, A.: Technical note: The libRadtran software package for radiative transfer calculations - description and examples of use, Atmos. Chem. Phys., 5, 1855-1877, doi:10.5194/acp-5-1855-2005, 2005.

Peña, O. and Pal, U.: Scattering of electromagnetic radiation by a multilayered sphere, Comput. Phys. Commun., 180, 2348-2354, doi:10.1016/j.cpc.2009.07.010, 2009.

Pozzer, A., de Meij, A., Pringle, K. J., Tost, H., Doering, U. M., van Aardenne, J., and Lelieveld, J.: Distributions and regional budgets of aerosols and their precursors simulated with the EMAC chemistry-climate model, Atmos. Chem. Phys., 12, 961987, doi:10.5194/acp-12-961-2012, 2012.

Pringle, K. J., Tost, H., Message, S., Steil, B., Giannadaki, D., Nenes, A., Fountoukis, C., Stier, P., Vignati, E., and Lelieveld, J.: Description and evaluation of GMXe: a new aerosol submodel for global simulations (v1), Geosci. Model Dev., 3, 391-412, doi:10.5194/gmd-3-391-2010, 2010a.

Pringle, K. J., Tost, H., Metzger, S., Steil, B., Giannadaki, D., Nenes, A., Fountoukis, C., Stier, P., Vignati, E., and Lelieveld, J.: Corrigendum to "Description and evaluation of GMXe: a new aerosol submodel for global simulations (v1)" published in Geosci. Model Dev., 3, 391-412, 2010, Geosci. Model Dev., 3, 413-413, doi:10.5194/gmd-3-413-2010, 2010 b.

Rothman, L. S., Jacquemart, D., Barbe, A., Chris Benner, D., Birk, M., Brown, L. R., Carleer, M. R., Chackerian, C., Chance, K., Coudert, L. H., Dana, V., Devi, V. M., Flaud, J.-M., Gamache, R. R., Goldman, A., Hartmann, J.-M., Jucks, K. W., Maki, A. G., Mandin, J.-Y., Massie, S. T., Orphal, J., Perrin, A., Rinsland, C. P., Smith, M. A. H., Tennyson, J., Tolchenov, R. N., Toth, R. A., Vander Auwera, J., Varanasi, P., and Wagner, G.: The HITRAN 2004 molecular spectroscopic database, J. Quant. Spectrosc. Ra., 96, 139-204, doi:10.1016/j.jqsrt.2004.10.008, 2005.
Scarnato, B. V., Vahidinia, S., Richard, D. T., and Kirchstetter, T. W.: Effects of internal mixing and aggregate morphology on optical properties of black carbon using a discrete dipole approximation model, Atmos. Chem. Phys., 13, 5089-5101, doi:10.5194/acp-13-5089-2013, 2013.

Tanre, D., Geleyn, J.-F., and Slingo, J. M.: First results of the introduction of an advanced aerosol-radiation interaction in the ECMWF low resolution global model, in: Aerosols and their Climatic Effects, edited by: Gerber, H. and Deepak, A., A. Deepak Pub., 133-177, 1984.

Toon, O. B. and Ackerman, T. P.: Algorithms for the calculation of scattering by stratified spheres, Appl. Optics, 20, 3657-3660, doi:10.1364/AO.20.003657, 1981.

Yang, W.: Improved recursive algorithm for light scattering by a multilayered sphere, Appl. Optics, 42, 1710-1720, doi:10.1364/AO.42.001710, 2003.

Zhang, K., O’Donnell, D., Kazil, J., Stier, P., Kinne, S., Lohmann, U., Ferrachat, S., Croft, B., Quaas, J., Wan, H., Rast, S., and Feichter, J.: The global aerosol-climate model ECHAM-HAM, version 2: sensitivity to improvements in process representations, Atmos. Chem. Phys., 12, 8911-8949, doi:10.5194/acp-12-89112012, 2012. 